\title{
Current trends in applications of magnetic ceramic materials
}

\author{
D BAHADUR* \\ Materials Science Centre, Indian Institute of Technology, Bombay 400076, India \\ ${ }^{*}$ On leave from Advanced Centre for Materials Science, Indian Institute of Technology, \\ Kanpur 208016, India
}

\begin{abstract}
Magnetic oxides, a major constituent of magnetic ceramic materials, are most extensively used in a variety of applications as soft, moderate and hard ferrites.I review here its applications with special emphasis on some recent developments in magnetic recording materials.
\end{abstract}

Keywords. Magnetic ceramic materials; their applications.

\section{Introduction}

Among the magnetic ceramics, magnetic oxides are the most important and rather the only relevant materials from the point of view of their applications. Magnetic oxides which are commonly known as ferrites are ferrimagnetic in structure as originally proposed by Neel (1948). The most common magnetic oxides which find wide applications as soft, hard or moderate ferrites are spinels, garnets and hexaferrites. Here I will limit this review to various applications of these oxides only. Comprehensive reviews on this subject are given by Standley (1972) and Wohlfarth (1982). The latest developments in the area of ferrites has been very well documented in the proceedings of ICF5 (Srivastava and Patni 1989). In this review, special emphasis will be given to magnetic recording materials and some typical results of the work in this area carried out in our laboratory will be presented.

\section{Magnetic oxides-some relevant properties}

The magnetic oxides (spinels, garnets and hexaferrites) by virtue of their structure can accommodate a variety of cations at different sites enabling a wide variation in properties. Further variation in synthetic methods can bring about large changes in some extrinsic properties. A majority of them are high resistivity materials making them more suitable for high frequency and low loss applications. Besides their resistance to oxidation, which is quite an advantage over metallic systems, they are also corrosion resistant. Spinels, $\mathrm{M}^{2+} \mathrm{Fe}_{2}^{3+} \mathrm{O}_{4}$, which are cubic with 8 formula units possess two sublattices. If all the $\mathrm{M}^{2+}$ ions go at the tetrahedral and $\mathrm{Fe}^{3+}$ ions at the octahedral sites, normal spinel is formed. The typical examples are $\mathrm{ZnFe}_{2} \mathrm{O}_{4}$ and $\mathrm{CdFe}_{2} \mathrm{O}_{4}$. When half of the $\mathrm{Fe}^{3+}$ ions go to the tetrahedral site while the rest to the octahedral site with $\mathrm{M}^{2+}$ ions, the inverse spinel such as $\mathrm{NiFe}_{2} \mathrm{O}_{4}$ or $\mathrm{MnFe}_{2} \mathrm{O}_{4}$ is formed.

Garnets $\left(\mathrm{Y}_{3}^{3+} \mathrm{Fe}_{5}^{3+} \mathrm{O}_{12}\right)$ are bcc cubic structures with 8 formula units and three sublattices. While $\mathrm{Fe}^{3+}$ ions distribute between octahedral and tetrahedral sites in 2:3 ratio, $\mathrm{Y}^{3+}$ ions (or rare earth ions) go to dodecahedral site. Substituted garnets and ferrites as soft ferrites find numerous applications. $\gamma-\mathrm{Fe}_{2} \mathrm{O}_{3}$ (which is also a spinel structure) has been widely used as magnetic recording material. Among hexaferrites, 
$M$-type $\left(\mathrm{BaFe}_{12} \mathrm{O}_{19}\right)$ and $W$-type $\left(\mathrm{BaMe}_{2} \mathrm{Fe}_{16} \mathrm{O}_{27}\right)$ are the most common because of their easy formation and wide applications. Besides, $X\left(\mathrm{Ba}_{2} \mathrm{Me}_{2} \mathrm{Fe}_{28} \mathrm{O}_{46}\right)$, $Y\left(\mathrm{Ba}_{2} \mathrm{Me}_{2} \mathrm{Fe}_{12} \mathrm{O}_{22}\right)$ and $Z\left(\mathrm{Ba}_{3} \mathrm{Me}_{2} \mathrm{Fe}_{24} \mathrm{O}_{47}\right)$ type hexaferrites are also known (Wohlfarth 1982). These are hexagonal crystal structures with a fairly large crystal anisotropy formed by superposition of $R\left(\mathrm{BaFe}_{6} \mathrm{O}_{11}\right), S\left(\mathrm{Me}_{2} \mathrm{Fe}_{4} \mathrm{O}_{8}\right)$ or $T\left(\mathrm{Ba}_{2} \mathrm{Fe}_{8} \mathrm{O}_{14}\right)$ blocks. For example, when successive $R$ blocks are interspaced by $S$ blocks, a $M$-type ferrite is formed, while when successive $R$ blocks are interspaced by two $S$ blocks, a $W$-type ferrite is formed. $T$ blocks are required in the formation of $Y$ or $Z$-type hexaferrites. Hexaferrites have been commonly applied as permanent magnets. Recently, they have also been exploited as recording materials which will be discussed later in this review.

\section{Applications of ferrites}

Ferrites are mainly classified into three categories based on their coercivity. Generally, most of the hard ferrites applications can be envisaged when the coercivity is $>1.5 \mathrm{~K} \mathrm{Oe}$. The $H_{c}$ of moderate ferrites lie within the range of $100 \mathrm{Oe}$ and $1.5 \mathrm{KOe}$ when most of the recording applications are feasible. For the soft ferrites, $H_{c}$ has to be very low $(<10 \mathrm{Oe})$. Soft ferrites can be further classified into two categories based on the low and high frequency applications. The growing applications of ferrites have been elucidated in figure 1 in the form of a tree after Hoshino (1980).

\subsection{Soft ferrites}

For the low and high frequency applications, the most important technical properties are $M_{s}, H_{c}, \mu_{i}$ and losses. It is generally not possible to obtain the best combination of these properties for any specific application. By varying the composition or adding additives or by varying the preparation technique, one can, to a large extent, control

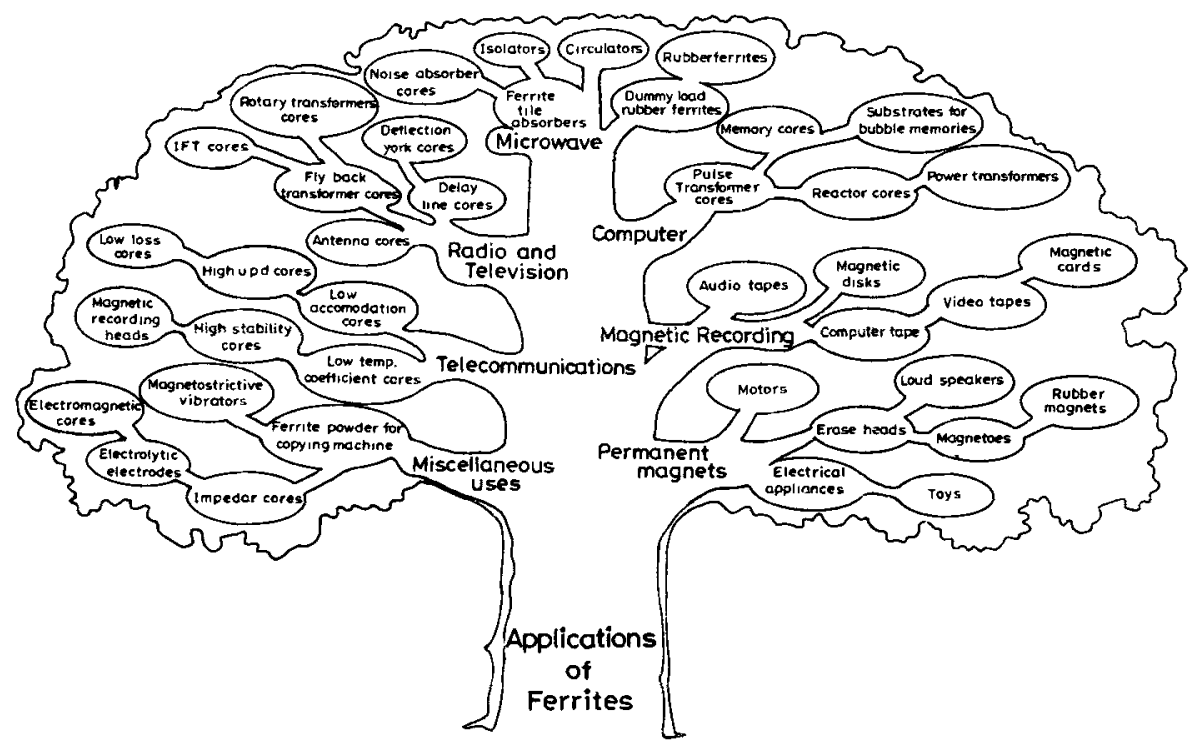

Figure 1. Wide range of applications of ferrites (symbolised after Hoshino 1980). 
most parameters required for any particular application. A comprehensive account of these are given by Das (1981). The largest consumption of soft ferrites is in television where almost half a kilogram is used for each set in the form of deflection yoke, UI core, $\mathrm{U}, \mathrm{L}, \mathrm{E}$ and $\mathrm{I}$ cores. $\mathrm{Mn}-\mathrm{Zn}$ ferrite has the most appropriate parameters for this application. A typical data for a good quality $\mathrm{Mn}-\mathrm{Zn}$ ferrite for the above application is as follows: $\mu_{i}=900 \pm 25 \%, B=3500 \mathrm{G}, \rho=10 \mathrm{Ohm} \mathrm{cm}, T_{\mathrm{c}} \sim 150^{\circ} \mathrm{C}$. Dimensional tolerances are quite critical. Because of low resistivity, $\mathrm{Mn}-\mathrm{Zn}$ ferrites are generally used up to $500 \mathrm{kHz}$ only.

Some of the other low frequency applications of soft ferrites include magnetic recording heads, inductor and transformer cores, filter cores, magnetostrictive vibrators and many other miscellaneous applications. However, each application warrants some different characteristics. Accordingly, the material has to be developed and tailor-made. For example, for magnetic recording head, besides low $H_{c}$, high $\mu$, thermal stability, wear and corrosion resistance, one also requires low magnetostriction and high frequency response. Amongst the ferrites, hot pressed and single crystal $\mathrm{Mn}-\mathrm{Zn}$ and $\mathrm{Ni}-\mathrm{Zn}$ ferrites are found quite suitable for this purpose. As regards the high frequency applications of these soft ferrites, high resistivity and passive dielectric properties are a must and the variation of RF permeability is important. The most important parameters which need to be evaluated are $4 \pi M_{s}, T_{c}, g_{\text {eff }}, \Delta H$, spin wave linewidth $\Delta H_{k}$, dielectric constant $\varepsilon$ and dielectric loss tangent, $\tan \delta$. High frequency applications include large number of microwave components such as circulators, isolators, gyrators, phase shifters, YIG tuned filters, switches and substrates for microwave integrated circuits. The materials which are generally known to be suitable for the above applications are substituted yttrium iron garnets such as YA1IG, YGdIG, YAIGdIG and spinel ferrites such as $\mathrm{Ni}-\mathrm{Zn}, \mathrm{Mg}-\mathrm{Zn}$ and $\mathrm{Mg}-\mathrm{Mn}$ ferrites. Typical data for Al substituted hot pressed YIG is as follows: $4 \pi M_{s}=1200 \mathrm{G}$, $g_{\text {eff }}=2 \cdot 00, \Delta H=40 \mathrm{Oe}, \Delta H_{\text {eff }}=4 \mathrm{Oe}, \Delta H_{k}=3.5$ and $\tan \delta=2 \times 10^{4}$.

\subsection{Hard ferrites}

Magnetic hardness is due to fine particles having shape and crystalline anisotropy. A large crystalline anisotropy is characteristic of hexaferrites. Hence, a large coercivity is almost an inherent property of hexaferrite and other than that it is oxidation- and corrosion-resistant. Its temperature stability is good and cheapest among all the hard magnets. By virtue of its low cost and being suitable $(B H)_{\max }$ for isotropic and anisotropic hexaferrites, it finds wide applications in motors, generators, loudspeakers, telephones, meter switches, magnetic separators, toys, flexible and rubber magnets, magnetic latch and magnetic levitation.

Among metallic systems, a number of alloys are superior property-wise. Still, due to reasons mentioned above, hexaferrites capture major portion of the hard magnet applications. To illustrate this, table 1 and figure 2 give the cost and percentage application comparison of hexaferrite magnets with other metallic magnets respectively. While table 1 shows that it is the cheapest among all the hard magnets, figure 2 exhibits the dominance of hard ferrites in the market. The projected growth in figure 2 for $\mathrm{NdFeB}$ is rather optimistic and according to experts, it could be even much lower. It is worth mentioning here that some of the unusual applications of ferrites include magnetic paints, vibration absorber, catalyser, artificial manure and several medical applications. Sugimoto (1984) discussed these applications in detail. 
Table 1. Cost comparison (with respect to weight and energy-product) of hexaferrite with other known metallic magnet systems.

\begin{tabular}{lcccc}
\hline & $\begin{array}{c}\text { Anisotropic } \\
\text { ferrite }\end{array}$ & Alnico & SmCo $_{5}$ & $\mathrm{NdFeB}$ \\
\hline $\begin{array}{l}\text { Energy product } \\
\text { in MGOe } \\
\text { in } \mathrm{MJ} / \mathrm{m}^{3}\end{array}$ & $3.6 \sim 4.3$ & $\sim 5.5$ & $18 \sim 20$ & 35 \\
\hline $\begin{array}{l}\text { Price } \\
(\$ / \mathrm{kg})\end{array}$ & $28.6 \sim 34.4$ & $\sim 44$ & $143 \sim 159$ & 275 \\
$\begin{array}{l}\text { Price } \\
(\$ \text { per Joule })\end{array}$ & $2.5 \sim 5$ & $25 \sim 35$ & $\sim 350$ & $\sim 570$ \\
\hline
\end{tabular}

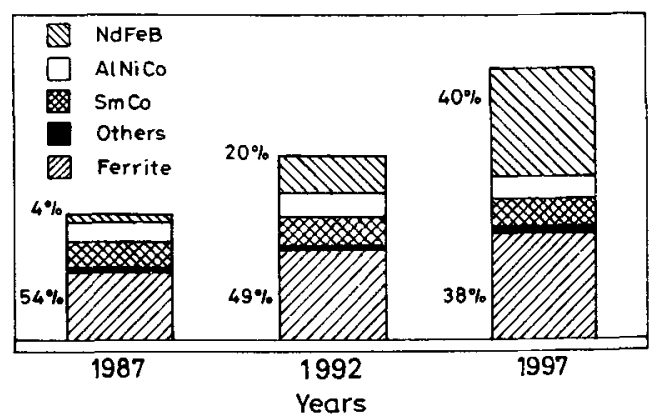

Figure 2. Projected applications of hexaferrite compared to other metallic alloy magnets.

\section{The world and Indian scenario}

Table 2 shows the estimated ferrite production in different parts of the world in 1990. The corresponding figure pertaining to 1979 is also shown for comparison. India's contribution is hardly $1 \%$ of the world's total output. Japan tops the list in the manufacture of both soft and hard ferrites. While in some countries, such as the US, UK etc. where labour is expensive, the production has decreased, in other countries such as South Korea and Taiwan (where labour is cheaper), the production has increased. Unfortunately, in India, there has been no increase in the production over these years. While only about $25 \%$ of our demand of soft ferrites for low frequency applications is being met by indigenous manufacture of hardly 600 metric tons per year, for high frequency applications, we are importing them.

As far as hard ferrite goes, the situation in the country is much better. In fact, the manufacturing of hard ferrites started in 1971 in this country. Now, there are a large number of manufacturers and the total capacity is about $6000 \mathrm{~T}$ per year. The world market for permanent magnet is very close to $\$ 2$ billion and is expected to grow to $\$ 3$ billion by 1997 .

\section{Magnetic recording materials}

Amongst the recording materials, the most exploited commercial materials are the discrete particles of magnetic oxides such as $\gamma-\mathrm{Fe}_{2} \mathrm{O}_{3}$ or $\mathrm{Co}$ doped $\gamma-\mathrm{Fe}_{2} \mathrm{O}_{3}$ and $\mathrm{CrO}_{2}$ 
Table 2. Estimated ferrite production (in tons) in different countries of the world in 1979 and in 1990 (after Ruthner 1989 in ref. 3).

\begin{tabular}{|c|c|c|c|c|}
\hline \multirow[b]{2}{*}{ Country } & \multicolumn{2}{|c|}{ Hard ferrites } & \multicolumn{2}{|c|}{ Soft ferrites } \\
\hline & 1979 & 1989 & 1979 & 1989 \\
\hline Canada & 4000 & 4000 & 3000 & 300 \\
\hline USA & 95000 & 75000 & 45000 & 10000 \\
\hline Mexico & 3500 & 2500 & 2800 & 400 \\
\hline Venezuela & 2500 & 1000 & 1500 & 200 \\
\hline Brasil & 15000 & 10000 & 5000 & 3000 \\
\hline Argentina & 3000 & 1500 & 2000 & 500 \\
\hline Chile & 600 & 600 & 400 & 200 \\
\hline Scandinavia & 1500 & 100 & 2000 & 300 \\
\hline Great Britain & 10000 & 6000 & 7500 & 6000 \\
\hline Spain & 3000 & 2500 & 2000 & 1000 \\
\hline France & 13500 & 13500 & 8000 & 8000 \\
\hline Germany & 12500 & 12500 & 9000 & 8000 \\
\hline Italy & 20000 & 18000 & 1500 & 200 \\
\hline Netherlands & 2500 & 200 & 3500 & 500 \\
\hline Yugoslavia & 1600 & 1600 & 1000 & 1000 \\
\hline Bulgaria & 1200 & 1500 & 600 & 800 \\
\hline Rumania & 1500 & 1500 & 800 & 800 \\
\hline Hungary & 1500 & 1500 & 1500 & 1000 \\
\hline CSSR & 3000 & 2500 & 2000 & 2000 \\
\hline Poland & 4000 & 2000 & 3000 & 1000 \\
\hline German Dem. Rep. & 16000 & 12000 & 8000 & 7000 \\
\hline USSR & 30000 & 30000 & 15000 & 15000 \\
\hline Egypt & 1500 & 1000 & 1000 & 200 \\
\hline Algeria & 1000 & 1000 & 1000 & 200 \\
\hline South Africa & 1000 & 1000 & 0500 & 200 \\
\hline China & 20000 & 25000 & 15000 & 12000 \\
\hline Japan & 85000 & 140000 & 50000 & 40000 \\
\hline India & 6000 & 6000 & 3000 & 3000 \\
\hline Indonesia & 2500 & 2500 & 1200 & 1200 \\
\hline Singapore & & 6000 & & $\begin{array}{l}500 \\
500\end{array}$ \\
\hline Thailand & & 3000 & & \\
\hline Malaysia & & & & 1000 \\
\hline Philippines & 1500 & 1500 & 1000 & 500 \\
\hline Australia & 1200 & 1000 & 600 & 500 \\
\hline Turkey & 1000 & 1000 & 500 & 100 \\
\hline Israel & 600 & 600 & 300 & 200 \\
\hline Iran & 1500 & 1000 & 1000 & 500 \\
\hline South Korea & 6000 & 20000 & 4000 & 18000 \\
\hline North Korea & 2000 & 500 & 1500 & 200 \\
\hline Taiwan, China & 6000 & 20000 & 4000 & 14000 \\
\hline Total & 382200 & 431100 & 209700 & 159500 \\
\hline
\end{tabular}

(Sharrock 1990). The latest and yet not exploited enough is the fine particles of hexaferrites which derives the required magnetic coercivity from its magnetocrystalline anisotropy while other oxides, as mentioned above, possess the requisite coercivity due to acicular nature. The coercivity, $H_{c}$, is perhaps the most important parameter to be controlled for a good magnetic recording material. Low $H_{c}$ gives poorer wavelength 
and frequency response whereas high $H_{c}$ would require very high bias and erase currents. Therefore, a compromise is required between these two limits. The suitable range is anywhere between $300 \mathrm{Oe}$ and $1.5 \mathrm{KOe}$ depending upon the specific requirement.

Besides the appropriate coercivity, $H_{c}$, saturation magnetisation, $M_{s}$ should be high enough to optimize the output and $M_{r} / M_{s}$, which determines the tape output, should be as close to 1 as possible. The other important basic property is the particle size which needs to be controlled. It should be large enough to provide adequate stability against time dependent magnetic effects. On the other hand, for high signal to noise ratio, narrow transitions, smooth tape and disc surface requires very small particles. Again, a compromised particle size is necessary. An excellent combination of the above mentioned properties should be accompanied by structural, wear and frictional characteristics which depend upon the organic components used for making dispersion.

As pointed out earlier, of late, barium hexaferrite is gaining popularity as a magnetic recording media (Speliotis 1987; Sharrock 1990). Already, high density flexible discs using barium hexaferrite is available commercially (Yamamovi et al 1986) and is the most likely candidate for contact duplication of digital audio tapes (Okazaki et al 1989). Barium hexaferrite has some obvious advantages over many other recording media. These are high density recording (with a possibility of perpendicular recording), lower cost, easier production, superior high frequency response and its stability and inertness. Besides, coercivity can be changed over a wide range without much reduction in $M_{s}$. A variety of synthetic methods have been developed to achieve a wide range of shapes, sizes and coercivities (Nagai et al 1985; Bahadur and Chakravorty 1989; Marcello et al 1989; Brahma et al 1990). One of the synthetic methods widely investigated in the last few years is through glass ceramic route whereby a large control of the above mentioned parameters is possible by small changes in composition, heat-treatment and using nucleating agents (Kubo et al 1982; Ram et al 1986a,b,c; Bahadur and Chakravorty 1989). In the next section, we discuss some of our own results on hexaferrites synthesized through glass ceramic route.

\section{Hexaferrite through glass ceramic route}

The glass ceramic route yields intimate mixing of ions. at the atomic level with subsequent nucleation and growth at lower temperatures. It also prevents large scale grain growth which is rather common in conventional ceramic route. Apart from this, it yields high strength ceramics due to pore-free uniform microstructure. Also, a fine control of the grain size and shape and its magnetic properties is possible through the appropriate use of nucleating agent and heat-treatment. In the light of these advantages, we have investigated crystallization of hexaferrites in $\mathrm{Mo}-\mathrm{Fe}_{2} \mathrm{O}_{3}-\mathrm{B}_{2} \mathrm{O}_{3}$ based glass system ( $\mathrm{M}=\mathrm{Ba}, \mathrm{Sr}, \mathrm{Ca}$ and $\mathrm{Pb}$ ) (Ram et al 1986a, b, c, 1987, 1988). Also, in many cases up to $1 \mathrm{~mol} \%$ of nucleating agents of $\mathrm{Bi}_{2} \mathrm{O}_{3}, \mathrm{P}_{2} \mathrm{O}_{5}, \mathrm{Ag}_{2} \mathrm{O}, \mathrm{As}_{2} \mathrm{O}_{3}, \mathrm{Sb}_{2} \mathrm{O}_{3}$ and $\mathrm{TiO}_{2}$ were used which influence the reaction kinetics considerably. Hence, the resultant glass ceramics exhibit a large variation in magnetic and other relevant properties. Table 3 gives some typical results for $\mathrm{Ba}$ hexaferrite based glass ceramics with different nucleating agents.

A significant variation in magnetic properties and volume fraction is indicated with 
Table 3. Some typical results of hexaferrite based glass ceramics with different nucleating agents in nominal composition $35 \mathrm{MO}-33 \mathrm{Fe}_{2} \mathrm{O}_{3}-$ $32 \mathrm{~B}_{2} \mathrm{O}_{3}(\mathrm{M}=\mathrm{Ba}, \mathrm{Ca})$.

\begin{tabular}{|c|c|c|c|}
\hline NA used & $\begin{array}{l}\text { Hexaferrite phase and its } \\
\text { maximum volume fraction }\end{array}$ & $\begin{array}{c}\text { Ms at } \\
10 \mathrm{KOe}\end{array}$ & $\begin{array}{l}\text { Coercivity } \\
\text { range } \\
\text { (Oe) }\end{array}$ \\
\hline \multicolumn{4}{|l|}{$M=B a$} \\
\hline $\mathrm{Bi}_{2} \mathrm{O}_{3}$ & $70 \% \mathrm{M}$ phase & $\sim 40$ & $650-3600$ \\
\hline $\mathrm{Ag}_{2} \mathrm{O}$ & $65 \% \mathrm{M}$ phase & $\sim 35$ & $50-2000$ \\
\hline $\mathrm{P}_{2} \mathrm{O}_{5}$ & $42 \% \mathrm{M}$ phase & $\sim 25$ & $800-1200$ \\
\hline $\mathrm{TiO}_{2}$ & $\begin{array}{l}\text { Completely inhibits the } \\
\text { growth of M-phase }\end{array}$ & $\begin{array}{l}\text { negli- } \\
\text { gible }\end{array}$ & 50 \\
\hline $\mathrm{As}_{2} \mathrm{O}_{3}$ & $44 \%$ M-phase & 32 & $750-3600$ \\
\hline $\mathrm{As}_{2} \mathrm{O}_{3}^{*}$ & $48 \%$ W-phase & $\sim 38$ & $3500-5300$ \\
\hline \multicolumn{4}{|c|}{ When $M=C a$} \\
\hline $\mathrm{Ag}_{2} \mathrm{O}$ & $25 \%$ M-phase & $\sim 17$ & $1100-1300$ \\
\hline $\mathrm{Bi}_{2} \mathrm{O}_{3}$ & $51 \% \mathrm{M}$-phase & 41 & $1200-1900$ \\
\hline $\mathrm{P}_{2} \mathrm{O}_{5}$ & $10 \% \mathrm{M}$-phase & 45 & 180 \\
\hline $\mathrm{P}_{2} \mathrm{O}_{5}^{* *}$ & $60 \% \mathrm{Ca}_{3} \mathrm{Fe}_{15} \mathrm{O}_{25}$ & 47 & $170-1100$ \\
\hline
\end{tabular}

NA = Nucleating agent used; * Very small change in nominal composition was done; ** also with $0 \cdot 1 \% \mathrm{As}_{2} \mathrm{O}_{3}$.

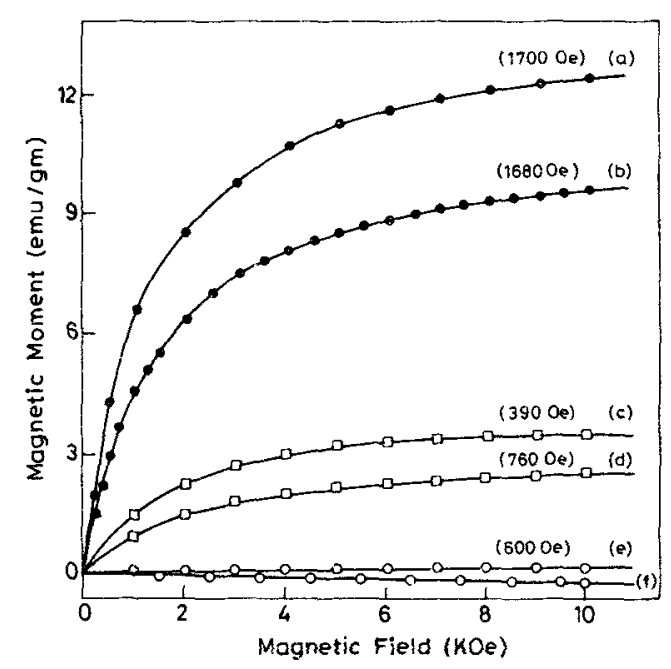

Figure 3. Plot of magnetisation vs magnetic field for composition $50 \mathrm{PbO}-, 20 \mathrm{Fe}_{2} \mathrm{O}_{3}-$, $30 \mathrm{~B}_{2} \mathrm{O}_{3}$ with different heat-temperature. Temperatures and duration are given in degree Kelvin and hours. (a) $725 / 2 \mathrm{~h}+765 / 25 \mathrm{~h}$, (b) $980 / 2 \mathrm{~h}+1060 / 2 \mathrm{~h}$, (c) $625 / 2 \mathrm{~h}+655 / 2 \mathrm{~h}$, (d) $850 / 2 \mathrm{~h}+925 / 2 \mathrm{~h}$, (e) $625 / 2 \mathrm{~h}+765 / 2 \mathrm{~h}$ and (f) $850 / 2 \mathrm{~h}+970 / 2 \mathrm{~h}$. Values of coercivities are given in parenthesis along with each magnetization curve (after Ram et al 1986c).

respect to different nucleating agents used. Similarly, there is also a large variation in magnetic properties as a function of variation in the heat-treatment schedule even though no nucleating agent is used (Ram et al 1986c). For example, for composition 50 $\mathrm{PbO}-20 \mathrm{Fe}_{2} \mathrm{O}_{3}-30 \mathrm{~B}_{2} \mathrm{O}_{3}$, the magnetization vs field data for different heat-treated samples is shown in figure 3 . While sample $e$ essentially shows a paramagnetic 


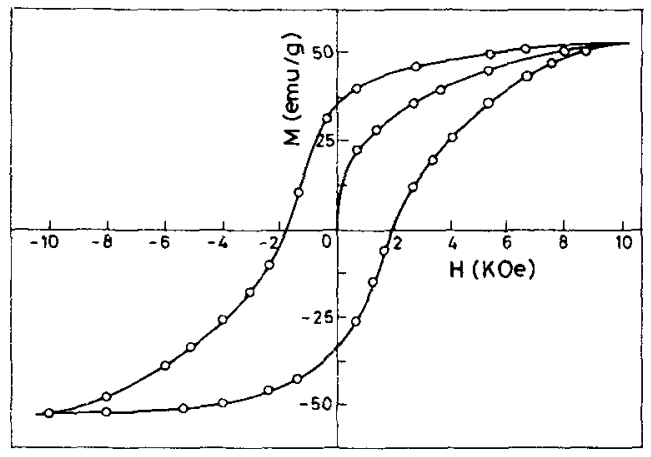

Figure 4. A typical hysteresis loop for a glass ceramic sample in composition $13 \mathrm{CaO}-$ $48 \mathrm{Fe}_{2} \mathrm{O}_{3}-39 \mathrm{~B}_{2} \mathrm{O}_{3}$ heat-treated at $1030 \mathrm{~K} / 2 \mathrm{~h}+1110 \mathrm{~K} / 2 \mathrm{~h}$ (after Ram et al 1988).

behaviour with a very low moment, sample $f$, on the other hand, is diamagnetic. All the other glass ceramic samples exhibit a much larger magnetic moment. But, they do not show saturation up to a field of $10 \mathrm{KOe}$. However, most of them exhibit high coercivity. The coercivity is indicated in parenthesis along with their respective magnetization curves for comparison (figure 3). A typical hysteresis loop for glass ceramic sample obtained after ceramizing the glass composition $13 \mathrm{CaO}-, 48 \mathrm{Fe}_{2} \mathrm{O}_{3^{-}}, 39 \mathrm{~B}_{2} \mathrm{O}_{3}$ at $1030 \mathrm{~K} / 2 \mathrm{~h}+1110 \mathrm{~K} / 25 \mathrm{~h}$ is shown in figure 4 . It exhibits a coercivity of $\sim 1800 \mathrm{Oe}$ and a large remanence. This glass ceramic has $M$-type $\mathrm{Ca} \mathrm{Fe}_{12} \mathrm{O}_{19}$ phase as much as $53 \mathrm{vol} \%$. It may be pointed out that $M$-type Ca-hexaferrite is not stable if synthesized through normal ceramic route. However, in the above mentioned composition, $M$-type hexaferrite could be stabilized through the glass ceramic route (Ram et al 1988).

Depending upon the nucleating agent used and heat-treatment given, the particle size could vary between hundreds of Angstroms to tens of microns (Ram et al 1986c, 1987,1988 ). In many cases, acicular particles with aspect ratio up to 26 were obtained while in many other cases platelets were obtained. In some cases, a large value of $M_{r} / M_{s}$ $(>0.8$ ) was obtained (Ram et al 1986b, 1987), particularly in case of Sr and Ba hexaferrite based glass ceramics. This is another important parameter to be controlled for magnetic recording applications. Therefore, most of the characteristics warranted for a good magnetic recording material are available in glass ceramic based hexaferrites. Attempts are underway to leach out the glass portion with suitable etchant to obtain a fine powder with the required properties for the magnetic recording applications.

\section{Acknowledgement}

This work was partially supported by CSIR, New Delhi.

\section{References}

Bahadur D and Chakravorty D 1989 Proceedings of ICF-5 (New Delhi: Oxford \& IBH Publishing Company) (eds) C M Srivastava and M J Patni 1189

Brahma P, Chakravorty D, Singh K and Bahadur D 1990 J. Mater. Sci. Lett. 91438

Das B K 1981 in Preparation and characterization of materials (eds) J M Honig and C N R Rao (New York: Academic Press) 
Kubo O, Idof T and Yokoyama H 1982 IEEE Trans. Magn. Mag. 181122

Marcello E D, Joubert J C and Mollard P 1989 Proceedings ICF-5 (New Delhi: Oxford and IBH Publishing Company) (eds) C M Srivastava and M J Patni 2899

Nagai N, Horilshi N, Kiyama M and Takada T U S 1985 Patent no. 4529524

Neel L 1948 Ann. de Phys. 3137

Okazaki Y, Noda M, Hara K and Ogisu K 1989 IEEE Trans. Magn. Mag. 254057

Ram S, Chakravorty D and Bahadur D 1986a J. Magn. Mag. Mater. 62221

Ram S, Bahadur D and Chakravorty D 1986 b Proc. XIV Int. Cong. on Glass, New Delhi (a special publication of Indian Ceramic Society) Vol. I, p. 336

Ram S, Bahadur D and Chakravorty D 1986c J. Non-Cryst. Solids 88311

Ram S, Bahadur D and Chakravorty D 1987 J. Magn. Mag. Mater. 67378

Ram S, Bahadur D and Chakravorty D 1988 J. Non-Cryst. Solids 101227

Sharrock M P 1990 MRS Bull. 1153

Speliotis D E 1987 IEEE Trans. Magn. 2325

Srivastava C M and Patni M J 1989 Advances in ferrites (New Delhi: IBM publishing company) Vols. I and II Sugimoto M 1984 in Recent advances in materials research (ed.) C M Srivastava (New Delhi: Oxford and IBH publishing company)

Standley K J 1972 Oxide magnetic materials (Oxford: Clarendon Press)

Wohlfarth E P 1982 Ferromagnetic materials (Amsterdam: North-Holland publishing company) Vol III Yamamovi K, Suzuki T and Fujiwara J 1986 IEEE Trans. Magn. Mag. 221188 